\title{
CARACTERIZAÇÃO MICROESTRUTURAL DO AÇO SAE 1080 APÓS DIFERENTES TRATAMENTOS TÉRMICOS*
}

\author{
Joshua Alyson Freitas Ribeiro ${ }^{1}$ \\ Diego Salmin Costa ${ }^{2}$ \\ Marcelo José Gomes da Silva ${ }^{3}$
}

\section{Resumo}

Aços com teores eutetóides, tratados termicamente são usualmente utilizados em trilhos metroviários. Para que sejam atingidas as propriedades mecânicas desejadas para as devidas aplicações, o material pode ser submetido a alguns tratamentos térmicos, como, por exemplo, Recozimento Pleno, Normalização e Têmpera. Os tratamentos térmicos são de extrema importância, pois possibilitam uma grande versatilidade na utilização dos aços em geral. Neste estudo, as peças utilizadas são provenientes de um trilho metroviário e foram fornecidas pelo Laboratório de Pesquisa e Tecnologia em Soldagem da Universidade Federal do Ceará. Foram feitas análises metalográficas após diferentes tratamentos térmicos em peças do Aço SAE $1080 \mathrm{Fe}-\mathrm{C}$ com o objetivo de verificar os aspectos microestruturais e a sua inflências no comportamento mecânico das amostras e a alteração nas propriedades mecânicas. Pelo fato do material estudado ter uma matriz com composição perlítica de, aproximadamente, $100 \%$, são mostradas as consequências devido à mudança nos espaçamentos interlamelares provocados pela aplicação de diferentes tratamentos e a influência da fase martensita na dureza do material.

Palavras-chave: Aço 1080; Microestrutura; Tratamento térmico

\section{MICRO-STRUCTURAL CHARACTERIZATION OF SAE 1080 STEEL AFTER DIFFERENTS HEAT TREATMENTS}

\section{Abstract}

Thermally treated steels with eutectoid composition are normally used in subway tracks. To obtain the desired mechanical properties for the especific aplications, the material may be submitted to some heat treatments, such as, Plane Annealing, Normalization and Quench. The Heat Treatments are extremally importante, because it is a method to improve the mechanical properties without changing the chemical composition. In this study, the microstructural caracterization was evaluated on subway track samples that were provided by Laboratory of Research and Tecnollogy in Welding. Metalographic analyses were done after different heat treatments in SAE $1080 \mathrm{Fe}-\mathrm{C}$ steel samples with the aim of verifying the influence in the microstructural and mechanical aspects of the samples. The material as recieved presented a matrix with, aproximally, $100 \%$ perlithic composition and due to the heat treatments, the material went through phase transformations, thus altering the interlamellar spacing and by consequence its hardness.

Keywords: Metalographic; Microstructural analysis; Heat treatment

1 Engenharia Metalúrgica, Graduando, Aluno, Departamento de Engenharia Metalúrgica e de Materiais, Universidade Federal do Ceará, Fortaleza, Ceará, Brasil.

2 Engenharia Metalúrgica, Graduando, Aluno, Departamento de Engenharia Metalúrgica e de Materiais, Universidade Federal do Ceará, Fortaleza, Ceará, Brasil.

3 Engenharia Mecânica, Doutor, Professor, Departamento de Engenharia Metalúrgica e de Materiais, Universidade Federal do Ceará, Fortaleza, Ceará, Brasil 


\section{INTRODUÇÃO}

Um tarugo cuja aplicação seria em trilhos metroviários foi fornecido pelo Laboratório

de Pesquisa e Tecnologia em Soldagem (LPTS). O material é denominado comercialmente como Aço SAE $1080 \mathrm{Fe}-\mathrm{C}$ cuja composição de Carbono em peso é tida na faixa eutetóide, ou seja, aproximadamente $0,77 \%$. A fim de analisar a microestrutura e a variação das propriedades mecânicas sob a influência de diferentes tratamentos térmicos, o material foi seccionado, preparado e analisado no Laboratório de Metalografia, Laboratório de Caracterização de Materiais (Lacam), Instituto de Pesquisa Desenvolvimento e Inovação (IPDI) e no Laboratório de Ensaios Mecânicos (LEM).

\section{MATERIAIS E MÉTODOS}

\subsection{MATERIAIS}

- Amostra de Aço SAE 1080 Como Recebida

- Amostra de Aço SAE 1080 Normalizada;

- Amostra de Aço SAE 1080 Recozida Plenamente;

- Amostra de Aço SAE 1080 Temperada;

- Máquina de Poli Corte (Cortadora Fortel II);

- Embutidora (arotec PRE $30 \mathrm{Mi}$ );

- Lixadeira (arotec Aropol 2V);

- Lixas de granulometria 100, 200, 320, 400, 600, 1200 mesh;

- Máquina de Polimento (arotec Aropol 2V);

- Panos para Polimento;

- Alumina $(0,5 \mu \mathrm{m})$;

- Microscópio Ótico (Zeiss Imager.M2m/ OlympusBZ51M);

- Máquina de Ensaio de Dureza Vickers;

- Microscópio Eletrônico de Varredura (Vega Tescan).

\subsection{METODOLOGIA}

\subsubsection{CORTE}

Por ter dimensões muito grandes $(33 \mathrm{~mm})$, as amostras foram particionadas para facilitar a análise e preparação. Para isso, foram levadas à máquina de poli corte cut-off, que realiza a partição do material por meio de discos abrasivos, no caso o disco utilizado foi o RISITEC T3, sendo importante frisar a necessidade da refrigeração para evitar-se alterações da microestrutura devido ao excesso de calor. Após a peça ser fixada, liga-se a bomba do fluido refrigerante e o motor do disco. Aplica-se cargas moderadas, para evitar a quebra do disco ou queima da peça. 


\subsubsection{EMBUTIMENTO}

O embutimento é um processo facilitador das próximas etapas da metalografia. A amostra é colocada na máquina embutidora e aplica-se a resina baquelita em uma quantidade suficiente para cobri-la por inteiro. A câmara de pressão é fechada, iniciando o processo. O conjunto baquelita-amostra é aquecido em altas pressões (deve-se manter a pressão do sistema em aproximadamente 150 $\mathrm{kgf} / \mathrm{cm} 2$ ) e temperaturas próximas à $170^{\circ} \mathrm{C}$. A resina ganha consistência dura e se adere à amostra, facilitando o manuseio desta. As amostras foram embutidas em baquelita, por meio da máquina de embutimento (arotec PRE $30 \mathrm{Mi}$ ).

\subsubsection{LIXAMENTO}

Com o objetivo de retirar as imperfeições mais grosseiras na superfície do material, realiza-se o lixamento. Foram utilizadas lixas de carboneto de silício, seguindo a seguinte sequência: 100, 240, 320, 400, 600 mesh. O fluido usado para resfriamento e lubrificação foi água corrente. As peças foram posicionadas e pressionadas na lixadeira giratória, e a cada lixa, mudou-se a direção de lixamento em 90ㅜ, tendo o cuidado de secar as amostras após cada troca de lixa, evitando assim, a oxidação enquanto as lixas foram trocadas. Vale ressaltar que somente após a uniformidade de riscos ser atingida, as lixas foram trocadas.

\subsubsection{POLIMENTO}

As amostras foram polidas, na lixa de 1200 mesh e em alumina de granulometria $0,5 \mu \mathrm{m}$. O principal objetivo do polimento é retirar os riscos e preparar as amostras para serem atacadas e vistas ao microscópio com uma boa qualidade. $O$ processo de polimento consistiu, no primeiro momento, em um processo semelhante ao lixamento, porém na lixa de grãos mais finos (1200 mesh). No segundo momento, usou-se o pano para polimento e nele aplicou-se alumina 0,5 $\mu \mathrm{m}$, água e um pouco de detergente para reduzir a probabilidade de riscos na peça. A amostra foi movimentada lenta e suavemente no sentido contrário ao da máquina até os riscos não serem mais vistos com o aumento de $50 \mathrm{X}$ do microscópio OlympusBZ51M no modo de iluminação campo escuro.

\subsubsection{ATAQUE QUÍMICO}

O ataque químico foi feito com nital 2\% (solução de $2 \%$ HNO3 e $98 \%$ de Álcool), por 5 segundos em todas as peças atacadas. Conforme indica Colpaert(2) "a concentração mais usual para metalografia de aços em geral é de $2 \%$ ". O procedimento foi realizado tomando-se todos os cuidados com a segurança do trabalho e ao descarte do reagente utilizado. Após preparada a solução, as peças foram imersas, uma de cada vez, e levemente agitadas no ácido reativo. Dado o tempo total de ataque, lavou-se imediatamente a peça com água corrente e álcool, depois a peça foi submetida à um jato quente, aplicado de maneira inclinada para evitar-se manchas na superfície. 


\section{RESULTADOS E DISCUSSÃO}

\subsection{AMOSTRA COMO RECEBIDA}

A figura 1 fornece a imagem da amostra como recebida, ao fim do procedimento metalográfico. De início, não se pode tirar conclusões prévias da amostra por meio de uma análise macroscópica.

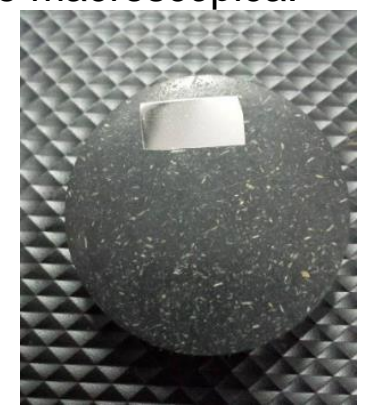

Figura 1. Macrografia Amostra Como Recebida após o polimento.

A figura 2 apresenta a micrografia realizada pelo Microscópio Óptico da amostra Como Recebida após a preparação metalográfica e ataque com nital $2 \%$ por aproximadamente 5 segundos.

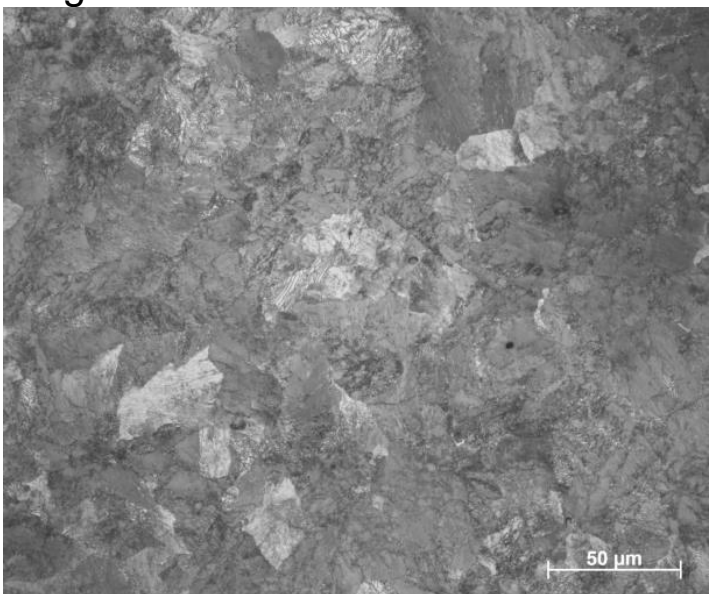

Figura 2. Micrografia da amostra Como Recebida após ataque químico com nital $2 \%$. Aumento de $500 x$

A Figura 3 apresenta a micrografia realizada pelo microscópio Eletrônico de Varredura da amostra Como Recebida preparada metalograficamente e atacada quimicamente com nital $2 \%$ por aproximadamente 5 segundo.

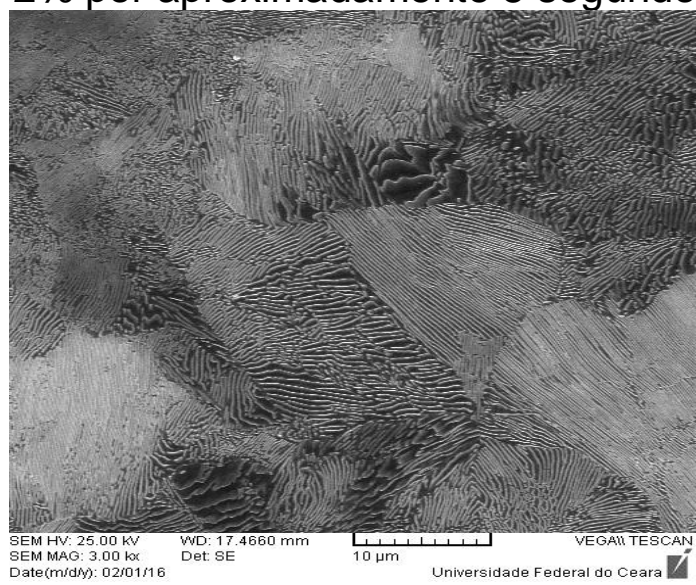

Figura 3. Micrografia da amostra Como Recebida após ataque químico com nital $2 \%$. Aumento de 3000x. 


\subsection{AMOSTRA RECOZIDA PLENAMENTE}

A figura 4 fornece a imagem da amostra Recozida Plenamente metalograficamente preparada. Entretanto, não se podem tirar conclusões mais aprofundadas da amostra por meio de uma análise macroscópica, semelhantemente a primeira.

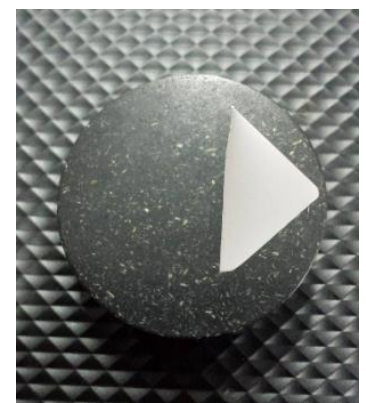

Figura 4. Macrografia Amostra Como Recebida após o polimento.

As figuras 5.a e 5.b apresentam a micrografia realizada pelo Microscópio Óptico da amostra Recozida Plenamente metalograficamente preparada e quimicamente atacada com nital $2 \%$ após, aproximadamente, 5 segundos.

a)

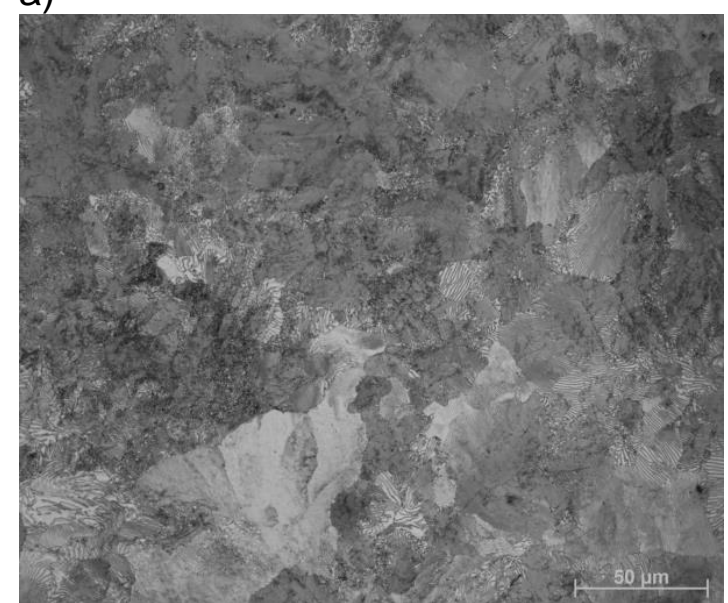

b)

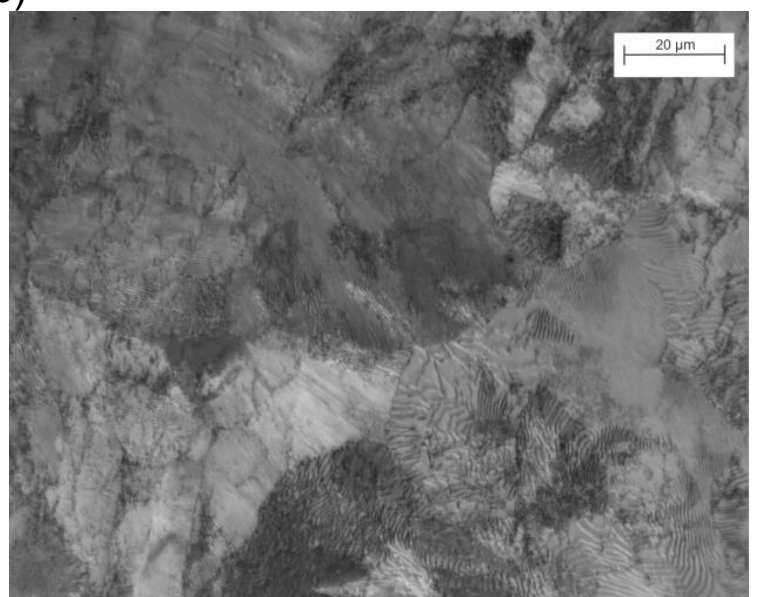

Figura 5. Micrografia da amostra recozida plenamente após ataque químico com nital 2\%. a) Aumento de 500x. b) Aumento de 1000x

As Figuras 6.a e 6.b apresentam a micrografia realizada pelo Microscópio Eletrônico de Varredura da amostra Recozida Plenamente preparada metalograficamente e atacada quimicamente com nital $2 \%$ por aproximadamente 5 segundos. 
a)
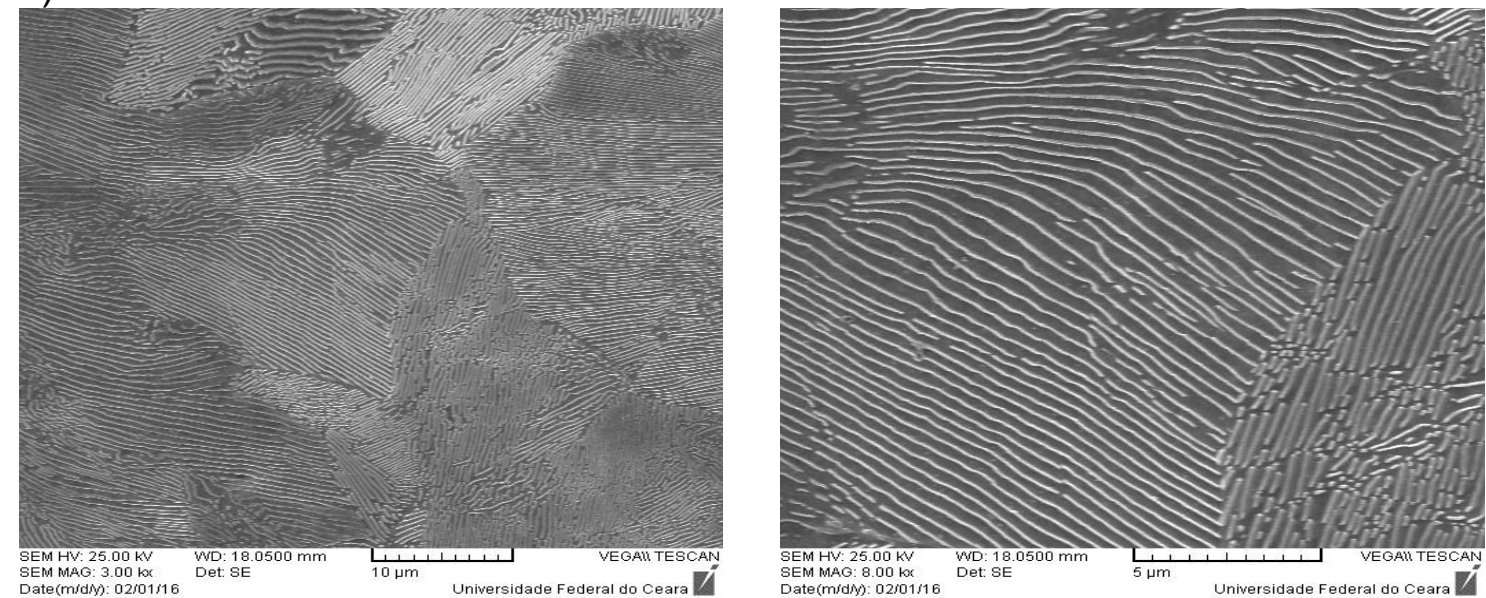

b)

Figura 6. Micrografia da amostra Recozida Plenamente após ataque químico com nital $2 \%$. a) Aumento de 3000x. b) Aumento de 8000x.

\subsection{AMOSTRA NORMALIZADA}

A figura 7 apresenta a imagem da amostra Normalizada, metalograficamente preparada. Entretanto, não se podem tirar conclusões mais aprofundadas da amostra por meio de uma análise macroscópica, semelhantemente as outras duas amostras citadas anteriormente no estudo.

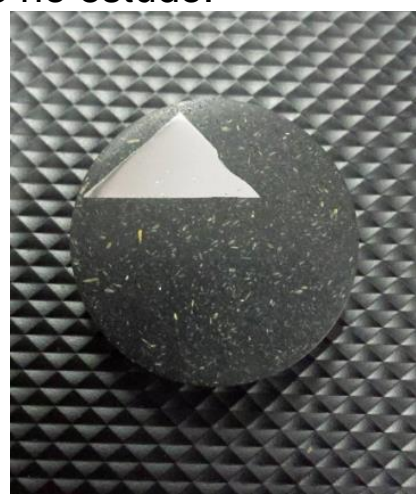

Figura 7. Macrografia Amostra Como Recebida após o polimento.

As figuras 8.a e 8.b apresentam a micrografia realizada pelo Microscópio Óptico da amostra Normalizada metalograficamente preparada e quimicamente atacada com nital $2 \%$ após, aproximadamente, 5 segundos.

a)

b)
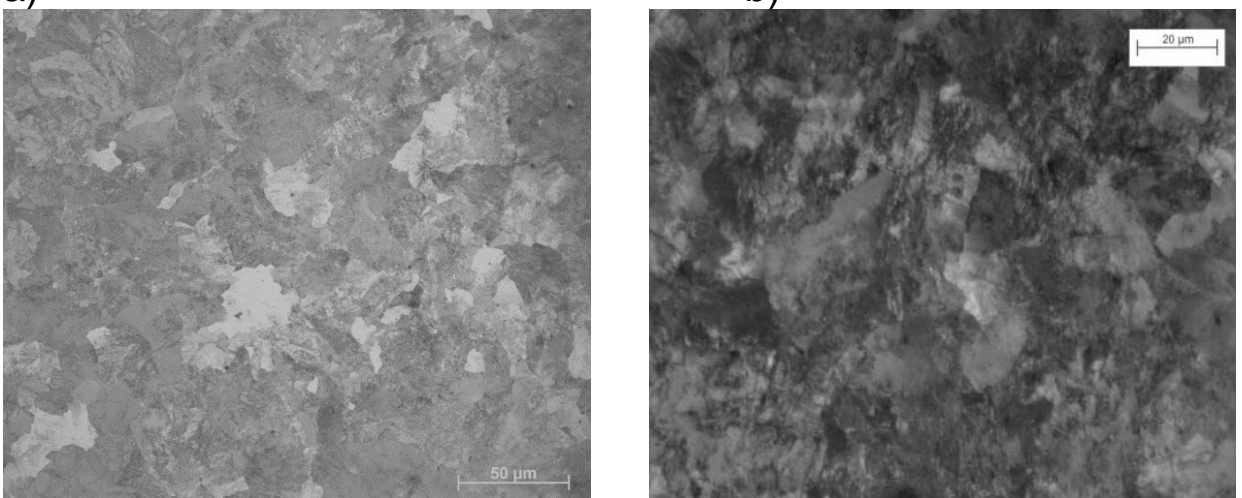

Figura 8. Micrografia da amostra normalizada após ataque químico com nital $2 \%$. a) Aumento de 500x. b) Aumento de 1000x 
As Figuras 9.a e 9.b apresentam a micrografia realizada pelo microscópio Eletrônico de Varredura da amostra Normalizada, preparada metalograficamente e atacada quimicamente com nital $2 \%$ por aproximadamente 5 segundo.

a)

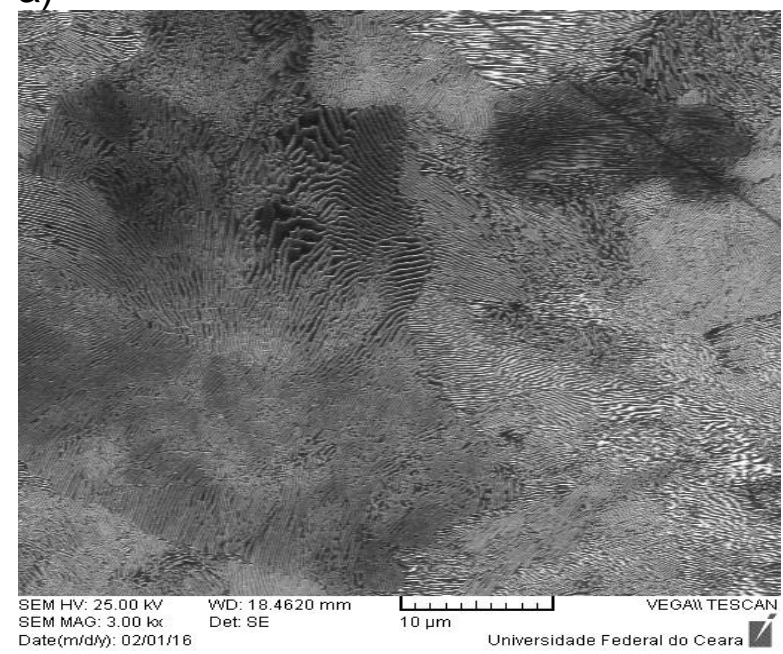

b)

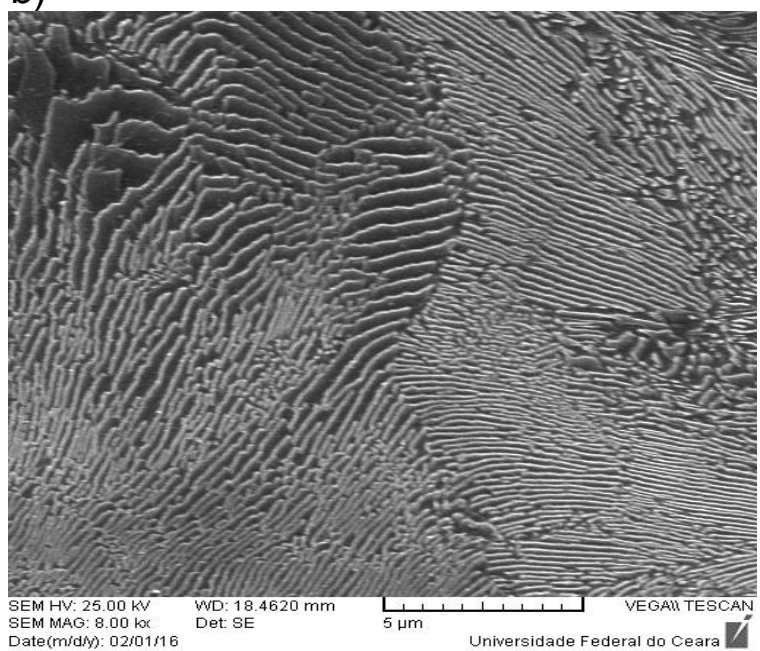

Figura 9. Micrografia da amostra Normalizada após ataque químico com nital $2 \%$. a) Aumento de 3000x. b) Aumento de 8000x.

\subsection{AMOSTRA TEMPERADA}

A figura 10 apresenta a imagem da amostra Temperada, metalograficamente preparada. Diferente das amostras até então apresentadas, a análise macrográfica dessa peça temperada nos induz a concluir que houve à formação de martensita pelo fato de ter aparecido uma trinca durante o tratamento de têmpera.

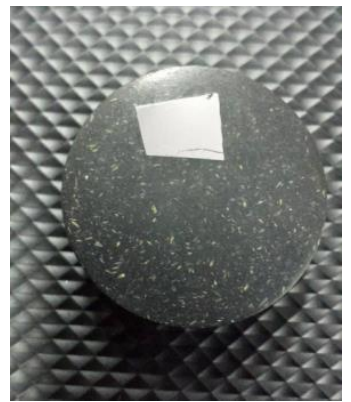

Figura 10. Macrografia Amostra Como Recebida após o polimento.

A figura 11 apresenta a micrografia realizada pelo Microscópio Óptico da amostra Temperada, metalograficamente preparada e quimicamente atacada com nital $2 \%$ após, aproximadamente, 5 segundos. 


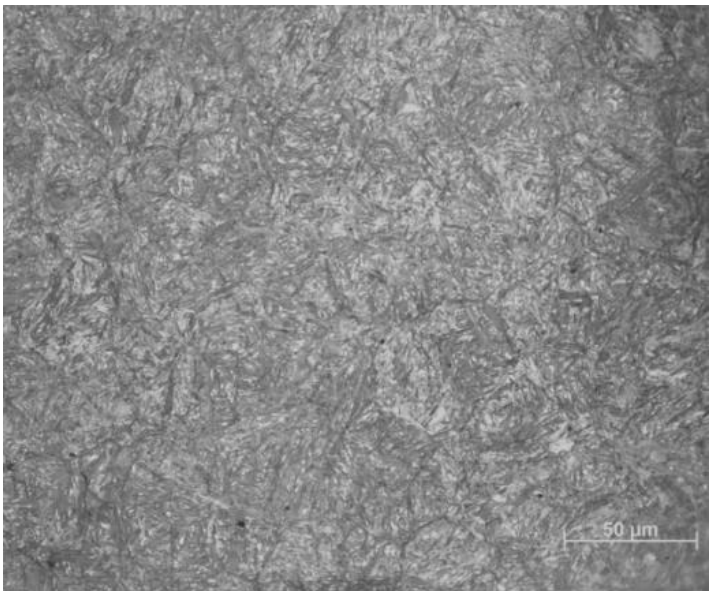

Figura 11. Micrografia da amostra temperada após ataque químico com nital $2 \%$. Aumento de $500 x$.

A Figura 12 apresenta a micrografia realizada pelo Microscópio Eletrônico de Varredura da amostra Temperada, preparada metalograficamente e atacada quimicamente com nital $2 \%$ por aproximadamente 5 segundo.

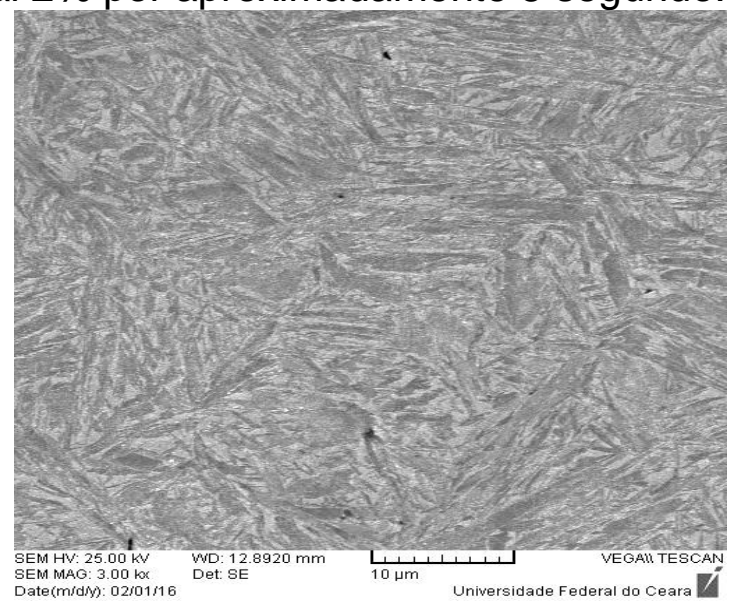

Figura 12. Micrografia da amostra Temperada após ataque químico com nital $2 \%$. a) Aumento de $3000 x$.

\subsection{ANÁLISE DA DUREZA}

O ensaio de dureza Vickers realizado em todas as amostras teve como carga aplicada $10 \mathrm{kgF}$. A equação utilizada para o cálculo da dureza Vickers foi a (Equação1):

$$
H V=1,854 \times\left(F / d^{2}\right) \times(1)
$$

Sendo $\mathrm{F}$ a carga utilizada no ensaio, $\mathrm{d}$ a média entre as diagonais da perfuração e HV o valor da dureza obtida pelo ensaio(3). 
Quadro 1. Resultados referentes às diagonais obtidas no ensaio de dureza Vickers

\begin{tabular}{|c|c|c|c|c|c|c|c|}
\hline Amostra & $\mathbf{d}_{\mathbf{1}}(\mathbf{m m})$ & $\begin{array}{c}\mathbf{d}_{\mathbf{2}} \\
(\mathbf{m m})\end{array}$ & $\begin{array}{c}\mathbf{d}_{\mathbf{3}} \\
(\mathbf{m m})\end{array}$ & $\mathbf{d}_{\mathbf{4}}(\mathbf{m m})$ & $\mathbf{d}_{5}(\mathbf{m m})$ & $\begin{array}{c}\text { Média } \\
\text { das } \\
\text { diago- } \\
\text { nais } \\
(\mathbf{m m})\end{array}$ & $\begin{array}{c}\text { Desvio } \\
\text { Padrão das } \\
\text { Diagonais } \\
(\mathbf{m m})\end{array}$ \\
\hline Temperada & 0,159 & 0,155 & 0,162 & 0,155 & 0,150 & 0,156 & 0,004 \\
\hline Recozida & 0,282 & 0,288 & 0,284 & 0,273 & 0,276 & 0,281 & 0,006 \\
\hline Normalizada & 0,238 & 0,247 & 0,249 & 0,252 & 0,260 & 0,249 & 0,008 \\
\hline CR & 0,259 & 0,255 & 0,253 & 0,255 & 0,258 & 0,256 & 0,003 \\
\hline
\end{tabular}

Fonte: autoria do aluno.

Quadro 2. Resultados referentes às durezas obtidas nos ensaios de dureza Vickers. HV é o resultado da dureza após a aplicação na fórmula. CM é referente à amostra Como Recebida

\begin{tabular}{|c|c|c|c|c|c|c|c|}
\hline Amostra & $\mathbf{H V}_{\mathbf{1}}$ & $\mathbf{H V}_{\mathbf{2}}$ & $\mathbf{H V}_{\mathbf{3}}$ & $\mathbf{H V}_{\mathbf{4}}$ & $\mathbf{H V}_{\mathbf{5}}$ & $\begin{array}{c}\text { Média das } \\
\text { Durezas }\end{array}$ & $\begin{array}{c}\text { Desvio Padrão das } \\
\text { Durezas }\end{array}$ \\
\hline Temperada & 733,36 & 767,23 & 708,63 & 774,19 & 821,26 & 759,5 & 42,87 \\
\hline Recozida & 233,47 & 222,83 & 230,11 & 248,31 & 243,38 & 235,35 & 10,25 \\
\hline $\begin{array}{c}\text { Normaliza- } \\
\text { da }\end{array}$ & 328,69 & 303,89 & 299,63 & 291,6 & 274,79 & 298,96 & 19,65 \\
\hline CR & 275,85 & 285,68 & 290,22 & 285,12 & 277,99 & 282,9 & 5,92 \\
\hline
\end{tabular}

Fonte: autoria do aluno.

\subsection{COMPARAÇÃO ENTRE OS ESPAÇAMENTOS INTERLAMELARES}

Ao obter as imagens no Microscópio Eletrônico de Varredura, com auxílio do software interno do equipamento foi possível comparar e calcular a diferença dos espaçamentos interlamelares entre as amostras Normalizada e Recozida Plenamente.

Quadro 3. Resultados referentes às distâncias medidas no Microscópio Eletrônico de Varredura Vegan Tescan

\begin{tabular}{|c|c|c|c|}
\hline Amostra & $\begin{array}{c}\text { Distância } \\
\text { entre as } \\
\text { lamelas } \\
\text { finas }(\mu \mathrm{m})\end{array}$ & $\begin{array}{c}\text { Distância } \\
\text { entre as } \\
\text { lamelas } \\
\text { grossas } \\
(\mu \mathrm{m})\end{array}$ & $\begin{array}{c}\text { Média } \\
\text { entre as } \\
\text { distâncias } \\
(\mu \mathrm{m})\end{array}$ \\
\hline Normalizada & 0,29 & 0,50 & 0,39 \\
\hline Recozida & 0,34 & 0,52 & 0,43 \\
\hline
\end{tabular}

Fonte: autoria do aluno.

\subsection{DISCUSSÃO DOS RESULTADOS}

A amostra Como Recebida apresentou uma matriz Perlítica(4) , como esperado, pelo fato do material ter teores eutetóides de Carbono em sua composição. Apesar de o ataque ter revelado bem a fase, a análise das lamelas nessa amostra apresentou dificuldades, pois a largura das mesmas não tinham dimensão o suficiente para que fossem analisadas no microscópio óptico. Em um 
primeiro momento, queria-se analisar a estrutura perlítica do aço Como Recebido, porém, pelo fato de as lamelas serem muito finas, não foi possível identificar com precisão o microconstituinte(5) no aumento de 500x no microscópio Zeiss Imager.M2m (Figura 2). Por causa desse empecilho, uma análise micrográfica foi feita no Microscópio Eletrônico de Varredura, a fim de observar as lamelas perlíticas presentes na amostra (Figura 3). Com as imagens obtidas pelo MEV, foi possível verificar a presença das lamelas de cementita (Fe3C) em meio aos veios de ferrita ( $\alpha-\mathrm{Fe})$, característicos da microestrutura perlita.

A amostra Recozida Plenamente após o preparo metalográfico, o ataque químico em nital $2 \%$ e a análise no microscópio óptico foi possível observar com uma maior facilidade as lamelas perlíticas. Com o aumento de 500x foi possível detectar pequenas regiões com estrutura perlítica bem definida (Figura 5.a). A fim de observar com mais detalhamento tais regiões, a amostra foi analisada em um aumento de 1000x no microscópio Olympus BZ51M. Novamente, a estrutura perlítica pôde ser identificada (Figura 5.b). Após isso, a amostra Recozida Plenamente foi levada ao microscópio eletrônico de varredura e foram obtidas duas imagens, uma com um aumento de 3000x e outra de 8000x (Figura 6.a e Figura 6.b). Com auxílio do software interno do MEV do IPDI foi possível realizar a medição entre as lamelas de cementita e calcular uma média entre elas, apesar desse resultado, não foi possível obter uma imagem com as marcações da medição, pois o software do equipamento apresentava algumas limitações e não concluía a função ordenada.

A amostra Normalizada foi analisada, primeiramente, no microscópio óptico, após toda preparação e ataque químico em nital $2 \%$. Semelhante à amostra Como Recebida, a peça Normalizada exerceu dificuldades na análise da microestrutura em um aumento de 500x (Figura 8.a). Todavia, em outro equipamento, o aumento de 1000x foi realizado (Figura 8.b) e a presença das lamelas de perlita foram localizadas, com muita dificuldade, mais finas e discretas em relação a microestrutura presente na amostra Recozida Plenamente. Confirmando o que era esperado(6) . Semelhante à amostra Recozida Plenamente, foram obtidas micrografias com aumentos de 3000x (Figura 9.a) e de 8000x (Figura 9.b) no MEV, da peça Normalizada. Com a maior magnificação feita, foi possível calcular e analisar o espaçamento interlamelar, com isso uma média foi feita entre as lamelas grossas e finas (Quadro 3). Sendo assim, pode-se confirmar que o tamanho dos espaçamentos entre as lamelas é influenciado diretamente pela taxa de resfriamento durante o tratamento térmico realizado no material. Não só a metalurgia física do material é afetada, mas também, as propriedades mecânicas, como a dureza. Tal resultado foi comprovado com os ensaios de dureza Vickers, realizados no LEM, onde a amostra Recozida Plenamente apresentou uma dureza menor em relação à amostra Normalizada (Quadro 1 e Quadro 2).

Por último, a amostra Temperada foi preparada metalograficamente e atacada quimicamente com nital $2 \%$. Por conseguinte, a amostra foi levada ao microscópio óptico e uma imagem com aumento de 500x foi obtida (Figura 11), revelando uma estrutura completamente martensítica, como já esperado por consequência do super-resfriamento realizado durante o tratamento(7). A amostra, também, foi analisada no MEV com aumento de 3000x (Figura 12) e a confirmação que realmente ocorreu transformação adifusional martensítica, novamente, foi 
concretizada. Essa transformação diferencia-se das já comentadas nesse estudo, pois nesse caso os carbonetos não sofrem influencia difusional significativa, mas a transformação se dá por meio do cisalhamento da rede devido ao alto estímulo termodinâmico acarretado pelo super-resfriamento, dando à estrutura, uma morfologia característica. Tal conclusão pôde ser evidenciada pelo ensaio de dureza Vickers, pois dentre todas as amostras ensaiadas (Quadro 1 e Quadro 2), a temperada apresentou o maior resultado de dureza, por conta das tensões internas residuais provocadas pela movimentação militar dos átomos(8). Não obstante, a concentração de carbono foi um parâmetro essencial para alcançar a dureza, pois o aço eutetóide tem uma concentração intermediária de carbono e isso otimiza o processo de tratamento térmico e o aumento da dureza por transformação martensítica.

\section{CONCLUSÃO}

A partir das análises microscópicas das amostras estudadas, foi possível determinar as fases presentes no aço em estudo. As amostras Como Recebida, Recozida Plenamente e Normalizada apresentaram grande uniformidade em suas microestruturas, devido ao alto teor de colônias de perlita, diferenciando apenas pela largura das lamelas. Por conta disso, o microconstituinte apresentou certa dificuldade de análise nas amostras Como Recebida e Normlizada, como já descrito por Callister [1]: "muitas camadas de cementita são tão finas, que as fronteiras entre as fases adjacentes estão tão próximas que não podem ser distinguidas sob ampliação de microscópio óptico". Sendo assim, foi feita a análise no microscópio eletrônico de varredura (MEV) para a comprovação da microestrutura.

$O$ reagente utilizado revelou os contornos de grão e a fase ferrita. Os resultados foram comparados com as micrografias presentes na obra Metalografia dos produtos siderúrgicos comuns, Colpaert [2]. As micrografias apresentaram alto grau de semelhança com a literatura, confirmando a composição do aço estudado com o Aço SAE $1080 \mathrm{Fe}-\mathrm{C}$ e a adequada caracterização do mesmo, revelando todas as fases esperadas (Perlita e Martensita).

Além disso, foi possível observar a influência da distância interlamelar na dureza do material, para as amostras Recozida Plenamente e Normalizada. Já na peça Tempera foi comprovado a dureza excessiva por causa do tratamento térmico efetuado. Tais resultados foram confirmados pelo padrão obtido nos ensaios de dureza.

\section{REFERÊNCIAS}

1 CALLISTER, W. D. Ciência e engenharia de materiais: uma introdução. 5a ed. Rio de Janeiro: Livros Técnicos e Científicos, p. 214. 2002.

2 COLPAERT, H. Metalografia dos produtos siderúrgicos comuns. Blucher. 4a edição, p. 115-116. 2008.

3 NOVIKOV, I. Teoria dos tratamentos térmicos dos metais. Rio de Janeiro. UFRJ, p. 15. 1994.

4 PORTER, D. A.. Phase Transformations in Metals and Alloys. London, U.K.. Chapman \& Hall, p. 406. 1992. 